\title{
The Digital Literacy Action Plan: A Strategy for Differentiation and Learner Agency in Digital Literacy Instruction
}

Rachel Riggs, World Education

Note: This paper reflects work that was undertaken while Rachel Riggs was affiliated with Frederick Community College.

\section{Abstract}

When I began my career in adult education as an adjunct ESL teacher, I felt well-equipped with an understanding of second language acquisition and evidence-based teaching methods. At the time, I knew nothing about digital literacy. Once I began to understand its importance and the challenges that it posed in the classroom, I developed the Digital Literacy Action Plan, an instructional strategy designed to differentiate, increase learner agency, and address digital equity concerns. This article is written for adult basic education instructors who aim to integrate digital literacy skills into their instruction in a way that is meaningful to each learner and empowers learners to acquire digital skills autonomously.

Keywords: digital literacy, instructional strategies, learner agency, differentiation, digital equity

When I began conceptualizing the Digital Literacy Action Plan (DLAP), there were two students in my Intermediate ESL class who aptly illustrated why differentiation and learner agency are so important in digital literacy. Helena is from Iran and her hand trembled on our first visit to the computer lab as she moved the mouse across the screen to sign in. The second, Michael, is from Côte d'Ivoire. He had recently enlisted in the U.S. Army and was able to convert an Excel spreadsheet into a bar chart sooner than I could sketch the same chart on a whiteboard. Helena wanted to use computers to support her children's education and Michael wanted to learn how to leverage technology for business management. I knew they each needed a completely personalized plan and as an educator I couldn't pass up the opportunity to facilitate their growth in this area.

\section{Understanding the Scope and Urgency of Digital Literacy}

As defined by the American Library Association, digital literacy is the ability to use information and communication technologies to find, evaluate, create, and communicate information, requiring both cognitive and technical skills (Visser, 2013). However, when I first heard the term, my understanding was limited. Per the requirements of the program I worked for, digital 
literacy pedagogy included visiting the computer lab five times per 10-week session, which amounted to about eight out of 60 instructional hours focused on digital skills. Many advised me to get my students set up with accounts on websites that offer free touch-typing practice. The digital literacy instruction I offered at the time was isolated from our work in the classroom and somewhat random as I haphazardly reserved time in the computer lab to fulfill that five-visit requirement. As I chose objectives for the time in the computer lab, I realized that whatever I chose, whether it was creating an email address, using a typing program, or formatting a document, there were students that flew through the activity while others took the entire time just signing in. A learner's success in these tasks was not predictable based on their reading, writing, listening, or speaking skills, resulting in a group of students whose English proficiency may be similar but whose digital literacy differed greatly, adding to the challenge of defining a set of objectives.

Between class time, lesson planning, and the occasional computer lab visit, I researched digital literacy and participated in professional development around the topic offered by the college and other organizations. At the Maryland TESOL fall conference, I was first introduced to the Maryland Department of Labor Digital Literacy Framework for Adult Learners (2019). The framework defines seven essential elements of digital literacy necessary for adult learners to function in an increasingly tech-driven society: technical, civic, communicative, collaborative, computational thinking, investigative, and productive. Reading and understanding the framework was a first step toward recognizing that the scope of digital skills that the learners in my classroom needed was broader than just the technical skill of touch-typing or the communicative skill of using email.
Eventually, digital literacy research led me to information and increased awareness around digital exclusion and how it impacts English learners, in particular. The National Skills Coalition (2020) reports that $40 \%$ of workers with limited English have no digital skills and only eleven percent have advanced skills. This critical equity issue directly impacts the learners in my classroom and shifts my view of digital literacy integration from something I was required to do to something I am compelled to do, effectively and systematically. Given the scope of digital skills and the urgency of digital upskilling, differentiation and learner agency are two challenging but key practices to apply in digital literacy integration. Adult learners facing digital exclusion should be given the options and agency within the classroom to work toward acquiring digital skills that are immediately relevant to their life, work, and educational goals. Recognizing that the trips to the computer lab and my prescriptive digital learning objectives were falling short, I formulated the DLAP to implement digital literacy in a way that addresses differentiation and learner agency.

\section{Origin of the DLAP}

Once I recognized the disparity between Michael and Helena's goals, but the common need and desire for digital skills, I decided to administer a survey to the class asking them what they wanted to do with technology and how it fit with their life goals. Then, I suggested possible resources, websites and what to search for, and had them each create a plan for how they would use their time in the computer lab. Michael wanted to learn a program that our school computers didn't have. So, we worked together to brainstorm ways that he could research Microsoft Access features without the program itself, look into comparable products, and analyze whether, when, and how 
he could purchase the program to be used in his company. Helena was not quite ready to jump into emailing and using Coogle Classroom so I helped her identify which technical skills she needed to get there and what resources were available. On the next visit to the computer lab, Michael watched YouTube tutorials on how to use Microsoft Access for project management while Helena did "mousercise" and started a typing program. The DLAP was integral in creating this personalized, concierge method of addressing each student's specific needs.

Of course, from a teacher's perspective, creating a personalized learning plan for each learner is not always practical. I began experimenting with different ways to formalize this approach to include higher learner involvement, phases that incorporated learning at various levels of complexity, and integration into the other learning objectives of the class. To increase learner-centeredness, I created a tool that students could use for planning and tracking their progress. (Figure 1) Then, I structured the creation and completion of the DLAP into four steps in order to engage learners on all cognitive levels and weave the DLAP, and the awareness of how technology impacts all aspects of life, into what we were doing in the classroom. Thus, the design of the DLAP was intended to be a practical solution to integrating digital literacy into language learning in a way that recognized the individuality of the learner and the critical issue of digital equity.

\section{The DLAP}

The DLAP is a plan students create to align the acquisition of digital literacy skills with their individual goals, choosing their own learning objectives, resources, and device(s). The instructor facilitates the process by providing guidance, scaffolding, feedback, and class time for learners to develop and execute their DLAP. It is helpful to use a digital skills framework, like the Maryland Digital Literacy Framework (2019), to organize and guide the process of creating a digital literacy action plan. The ideal result of creating and completing the DLAP, in addition to developing digital literacy skills, is to facilitate a process that supports adult learners in developing strategies and confidence that will assist them in lifelong learning and digital resilience.

\section{Step One: Goal Setting, Connecting Digital Literacy to Life Goals}

The first step in the DLAP is to include digital skills in a goal-setting lesson at the start of the class session. From my observations, instructors usually practice this in some form, as they use a discussion of goals at the start of a class to get to know and motivate learners. The DLAP takes this one step further by determining what role digital skills and technology (internet, devices, media, etc.) play in reaching a learner's goals. During this lesson, the objective is to show learners that digital skills are connected to all aspects of life. If we begin the discussion at the outset of the class, the rationale for creating a DLAP becomes clear. This goal-setting phase will establish the relevance of digital skills to all learners, leveraging their goals in other areas to spark interest and motivation for creating a DLAP.

Consider Helena and Michael. Imagine that life, work, and education were written on the whiteboard with large circles around them for students to write in their goals. Helena might have come to the board and written nothing in the work or education bubbles. Her main goal for learning English was to support and stay connected with her children. For Michael, on the other hand, the work bubble would have been filled in with his desires to upskill in business management. Now imagine that there's a larger circle drawn around the three 
bubbles with the label technology. While learners may not be able to identify goals in all three areas of life, work, and education, this simple visual will show them that no matter which of those categories their motivation falls into, technology will play a role for all lifelong learners.

\section{Step Two: Planning}

After learners have identified which digital skills they need to reach their goals, they move into the planning phase. This phase entails breaking down their overall goal into a set of steps, attaching a timeline to each step, and listing resources they will use. The instructor's role in the second step of the DLAP is to help students by suggesting resources and assisting with setting a realistic timeline.

The resources offered to learners could be a list of multiple suggested materials (e.g., websites) or a single recommendation. Again, this is where having a framework and supplemental materials is helpful. With or without a framework, it's important to build and maintain a list of open resources to recommend to students. When suggesting resources consider ease of use, accessibility, and planning.

\section{Suggested Resources}

1. GCF Learn Free Technology Tutorials (GCFGlobal.org)

2. DigitalLearn.org

3. Google Applied Digital Skills (applieddigitalskills.withgoogle.com)

\section{Step Three: Learning}

Once goals have been defined and plans are set out, the learning phase begins. During this step, students will begin to work through their timeline, utilizing the resources they have selected to achieve the learning objectives they have set for themselves. I always include time within our normal class periods for students to work on, discuss, and receive feedback on their progress (see Figure 2 for an example timeline). Since they will have unique action plans, each student will be working independently. However, group discussions and regular check-ins will help foster a sense of community during the process.

It is important to remember that each step in this process will be more of an art than an exact science, and that will become clear during this third step. Students will discover that a certain resource isn't working for them. They may find out that their timeline was unrealistic. It is, of course, for that reason that teachers facilitate learning experiences. The key idea is that the learning takes place not just in the achievement of the final objective but through the analysis and trial-anderror that is involved throughout the process. Keep in mind that the act of setting goals, gathering resources, and analyzing the usefulness and validity of those resources are all important digital literacy skills in and of themselves.

There will be varying degrees of "success" when we talk about students acquiring that final goal. In Helena's case, by the end of the class session, she became much more comfortable navigating the mouse, signing in and out of the computer, opening web pages, and typing. She also learned that free and open resources exist with which she can gain a great many digital skills as she progresses on her learning journey toward becoming a more active participant in her children's education. Michael managed to get a better grasp on Microsoft Access by watching YouTube videos and visiting Microsoft forums. He also voluntarily assisted other learners with their action plans, strengthening his ability to lead and troubleshoot. From an outsider's perspective, perhaps the ideal result would have been to see 
Helena managing her own Coogle Classrooms or to hear that Michael had a lofty credential to add to his resume. While those outcomes would be wonderful, that is not the real aim of the DLAP. The purpose of the DLAP is not to achieve mastery, but to empower learners to set measurable digital literacy goals and leverage resources in order to acquire the skills necessary to be an informed and evolving digital citizen.

\section{Step Four: Reflection}

The final step in the DLAP is that of reflection. The reflection can be modeled around the first three of Carol Ann Tomlinson's (1999) methods for differentiating instruction: content, process, and product. Consider creative ways to group students and different methods for reflection. For example, a group of students could prepare a brief presentation on what they aimed to learn, their opinion of the DLAP process, and the outcome. Being an English instructor, I try to always think about how I can incorporate language skills and forms throughout the process. Therefore, depending on the group I'm working with, the reflection could end up being a class discussion or a written essay. During the reflection, I elicit their thoughts on the resource(s) they used (content), how the DLAP assisted them (process), and what they were able to achieve (product).

\section{Conclusion}

After implementing the DLAP over time, I have seen its ability to encourage learners who once felt the daunting burden of digital literacy, as they took the reins and forged their own paths as legitimate and capable digital citizens. The DLAP offers digital literacy development that caters directly to students' goals, models the importance of planning, and provides time for learning, exploration, and reflection. Its inherently individualistic approach requires a lot of effort on behalf of both facilitators and learners. It is, however, an approach that prioritizes digital literacy instruction as an equity initiative and considers the individuality and dignity of adult learners. As the digital divide continues to widen, and especially in light of the complication presented by the coronavirus pandemic it is incumbent upon adult educators to collaborate and innovate in the integration of digital literacy. My sincere hope is that the DLAP will benefit learners and instructors as they navigate this crucial component of lifelong learning. 


\section{References}

Maryland Department of Labor. (2019). Digital literacy framework for adult learners. https://www.dllr.state. md.us/gedmd/digitalliteracyframework.pdf

National Skills Coalition. (2020). Applying a racial equity lens to digital literacy: How workers of color are affected by digital skill gaps. https://www.nationalskillscoalition.org/ resources/publications/file/Digital-Skills-RacialEquity-Final.pdf
Tomlinson, C. A. (1999). The differentiated classroom: Responding to the needs of all learners. Association for Supervision and Curriculum Development.

Visser, M. (2013). Digital Literacy and public policy through the library lens. Maine Policy Review, 22(1), 104-113. https://digitalcommons.library.umaine. edu/mpr/vol22/iss1/27 


\section{Figures}

FIGURE 1: DLAP Graphic Organizer

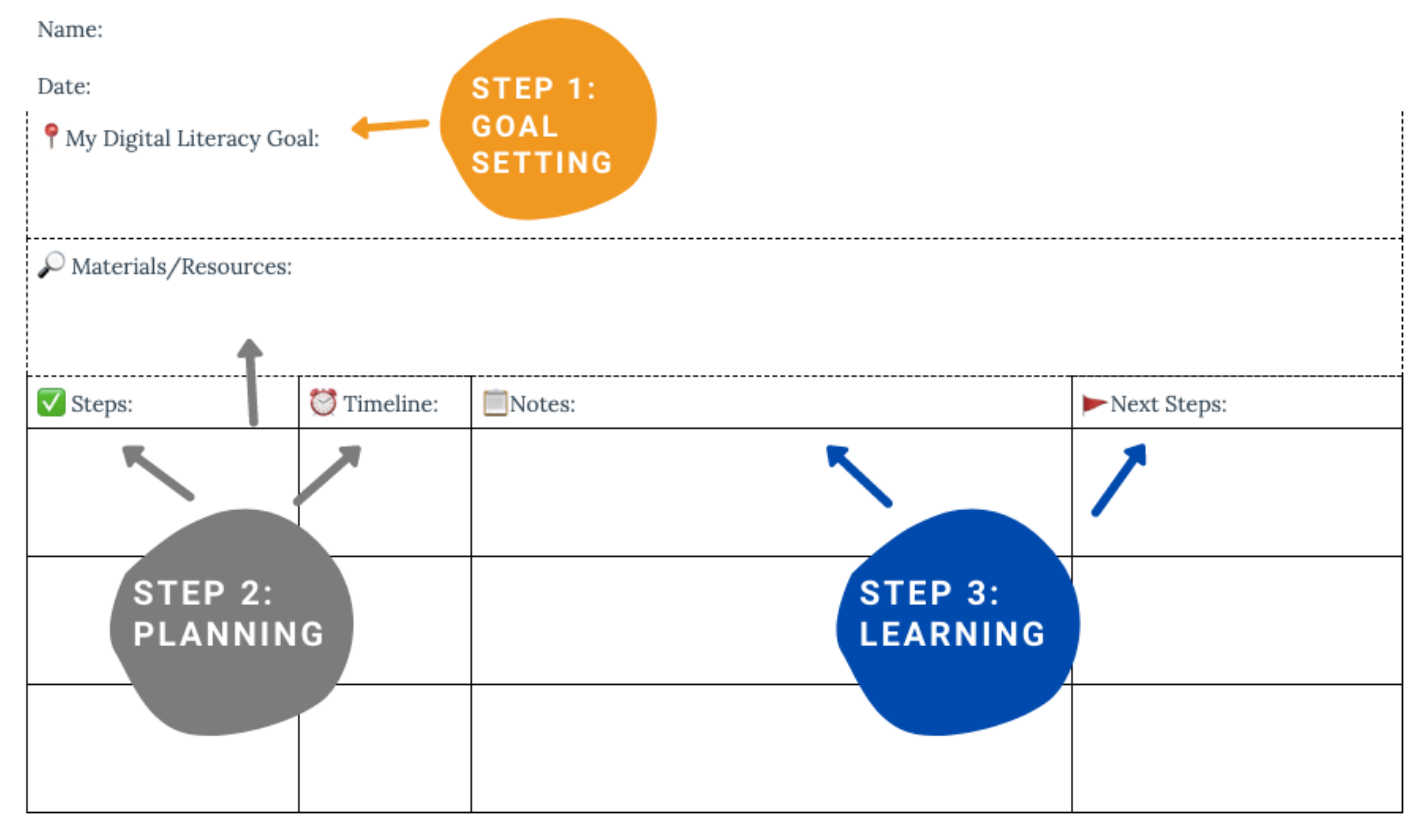

FIGURE 2: Example DLAP Timeline

\section{EXAMPLE DLAP TIMELINE -10 WEEKS}

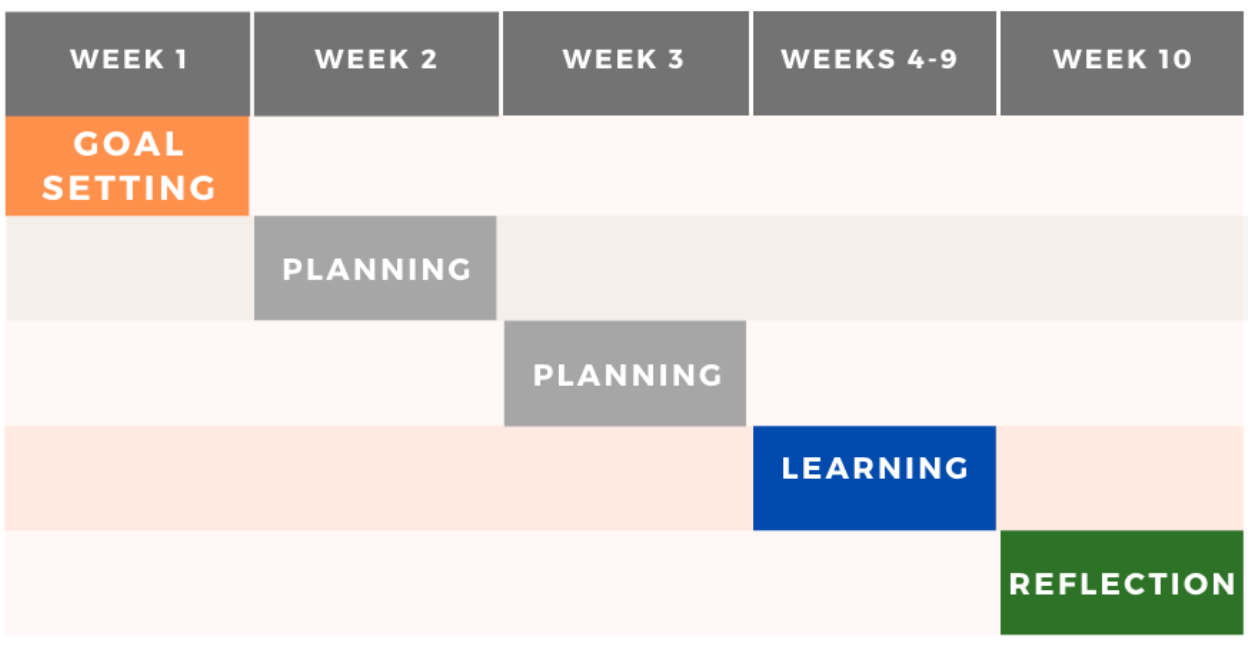

